\title{
Practice teaching in a global world
}

\section{Andrea Wild ${ }^{1}$ and Geoffrey Meads ${ }^{2}$}

Summary: The importance of interprofessional education (IPE) as a means of equipping health and social care professionals with the skills needed to work effectively in team-based and integrated services is recognised across the globe.

This paper highlights IPE developments that can inform practice and offers a framework of collaboration for the teaching of IPE.

Drawing on the findings from an international research programme the motivational forces for collaboration are presented and the implications for practice teachers considered.

Key words: Collaboration, interprofessional, transferable learning.

1. Senior Research Fellow, Centre for Primary Health Care Studies, Warwick Medical School.

1. Professor of Organisational Research, Warwick Medical School.

Address for Correspondence: Professor Geoffrey Meads, Warwick Medical School, University of Warwick, Coventry, CV4 7AL.g.d.meads@warwick.ac.uk 


\section{Introduction: Context and approach}

As a result of post-Millennium 'Modernisation', the context for health and social care practice is fundamentally changing. The term 'Modernisation' signifies an international pattern of policies for decentralisation, regulation, governance, innovative partnerships and national stewardship of social capital which taken together create a new environment for the local teaching of this practice. Overall the contemporary environment is characterised by a shift from individual profession to host organisation as principal locus of care, while at the same time the boundaries of health and social care organisational units have themselves become less fixed and more flexible. Alliances, cooperatives, networks and other forms of joint ventures abound as part of the general movement away from simple institutional or market models to complex systems based approaches rooted in relationships. For practice teaching collaboration in this context becomes both the educational process and the educational objective or outcome. Essential requirements for membership of a modern health and social care profession are interprofessional skills and competencies.

An awareness of this changing context led the UK Department of Health and London based Health Foundation in 2002 to commission a long term programme of research designed to promote 'transferable learning' between countries with parallel 'modernising' policy reforms in health and social care (Wild, Iwami, \& Meads, 2003). There was a particular UK interest, given the recent introduction across England of Primary Care Trusts with their multiprofessional management mechanisms, in novel community based organisational practices (Meads, Griffiths, Wild, et al, Forthcoming). Different approaches to both interprofessional learning and development and combining health and social services were defined as priority subjects for transferable learning. This article draws on some of the lessons that have emerged from this research programme, the detailed methodology of which has been reported elsewhere (Meads, Iwami, and Wild, 2005).

The aim of this article is twofold: first to highlight both collective and individual developments in interprofessional education (IPE) that can positively inform present practice; and secondly to offer a framework of collaboration for its future teaching.

On both counts there are new challenges and opportunities. The opportunities are especially apparent in practice teaching for social 
care given its longer history of service development across the statutory and non-statutory sectors. Health care education has historically been more unidisciplinary with less emphasis in curricula design on, for example, community development, teamwork, participation and networking. For social care practitioners, working with voluntary agencies, 'substitute' professionals and private enterprise partners has become standard practice and such learning is a pragmatic necessity. The tenets of modernisation now mean the same for their health care counterparts. With decentralisation, for example, come local resource management arrangements cutting across professions and communities. These range from the hybrid Primary Health Organisations of New Zealand that cluster the community based professionals of private general practices into unified public health programmes, to the various skill mixes tendered for by Thailand's Contracting Units for Primary Care (Meads, Ashcroft, Barr, et al. 2005).

The same applies to regulation and governance. These expressions of modernising policies usually involve the establishment of external monitoring and quality control mechanisms that examine corporate performance for which there is collective interprofessional accountabilities. The enforcement of evidence based treatments by Health Maintenance Organisations in the United States and Sickness Funds in The Netherlands are obvious examples from the North. From developing countries of the South so too are the Municipal Training Committees of Colombia which accredit practice teaching programmes for seven health and social care disciplines and the combined Ministry of Health and Social Welfare in Bolivia which oversees all local practice teaching needs through its integrated human resources strategies. The implementation of these is monitored by an independent National Accreditation Commission for all first level health and social care.

New partnerships and national stewardship of social capital are the other defining features of contemporary health and social care systems in a global context. Once again innovations in interprofessional learning and practice development are widespread and plentiful. Frequently in fact, new partnership models of service are the prerequisite of such external donors as the Salem Foundation and Care International which look to fortify national governments that have struggled previously to exercise their stewardship roles and responsibilities. Cuba and Costa Rica have, for many, been role models driving forward their 'Solidarity' programmes on the basis of integrated health and social care develop- 
ments that use such terms as 'Third Age' and 'Teaching to Learn' (rather than clinical conditions) to harness multi-professional and cross-agency energies. For modern Brazil, where the Kellog Foundation is a key sponsor, research as 'transdiscipline' is now promoted. Brazil, furthermore, is a country where past resistance to change has been such that one practice teacher told us it had been 'easier to change a cemetery than medical education'. The multidisciplinary integrated home care teams of Italian and Greek Regions benefit from being European Union pioneer pilots, while in Mexico the integration between professions seems more vertical than lateral in form, as trained community workers are used to identify and recruit potential future leading local health care professionals. Scandinavian cross-sectoral 'Care Chains', sub-Saharan generic 'Community Practice' and Malaysia's 'Train the Community' programmes for health and social care workers are just a few further illustrations of how interprofessional learning has become what one Sudanese medical teacher described to us as the 'soul' of the practice team and the spirit of its development. It is important that we begin by examining some of these global trends in more detail to discern the emergent IPE models.

\section{Global trends: learning together to work together}

There is international recognition, (World Health Organization, 1988; Mur \& van Raak, 2003) that the integration of services and collaboration of organisations and professionals within them should lead to more effective and efficient services. Demographic, epidemiological and therapeutic changes are occurring globally which necessitate team working and communication with others involved in health and social care across sectors, and new ways of collaborating are being enabled by technological advances. Decision making is routinely a multidisciplinary and therefore multiprofessional, although not always an educational process. In addition to learning how to work effectively with colleagues, health and social services professionals require new attitudes and skills that enable them to work with other sectors to provide comprehensive, high quality, continuous and personalised care which meets local needs (Alwan \& Hornby, 2002).

There is growing appreciation of the important role interprofessional 
education can play in equipping individual professionals with these skills. By interprofessional education we mean education provided to more than one profession, with interaction as an important goal and increased knowledge, understanding and collaboration as an outcome (Barr, Freeth, Hammick, et al. 2000). The sharing of knowledge is crucial to effective patient and client care, and shared learning can lead to an increased understanding and respect of other professions' roles, abilities and knowledge (Funnell, 1995). This increased understanding can help to dispel negative stereotypes, improve perception of the roles of others providing care within a team and lead to an increased confidence in communication amongst professionals (Barr, 2002). Improving communication between different professionals and sectors should lead to improved communication between professionals and service users.

Two popular approaches to shared learning found in many countries across the globe are action research and problem-based learning, both of which are rooted in practice. Such approaches have been found to be effective in terms of outcomes such as improved attitude, knowledge and understanding amongst different professionals. Action research seeks to promote change through research and involves collaboration between researcher and researched in defining the research issue, planning the conduct of the research and deciding how to use and disseminate the findings (Morton-Cooper, 2000).

Problem-based learning, pioneered in medical education by such universities as Maastricht in the Netherlands and McMasters in Canada, emphasises the importance of students solving real patient or community problems, under the supervision of a more experienced professional (Barrows \& Tamblin, 1980). Responsibility for patients as part of a team involved in patient care forms an important part of the assessment process within the medical education curriculum in such universities as Maastricht (Scherpbier, 2001) and McMasters and is reflected for social care by the approach of such new universities as Brighton and Anglia in the UK.

\section{The position in the UK}

In the UK, the promotion of collaboration and interest in interprofessional education has been a normative policy trend since the 1960s

9 Journal of Practice Teaching 5(3) 2004, pp.5-19 @ 2004. Whiting and Birch 
(Forman \& Nyatanga, 1999). Since 1997, its development has been regarded as a key element in the 'modernisation' of health and social care (Hargadon \& Staniforth, 2000), with proponents arguing that it facilitates the collaborative and partnership arrangements favoured in policy and is an essential element of the desire to provide a seamless service to users (Mur \& van Raak, 2003).

However, in the UK the critical issues to date have been around the identification of what interprofessional education means, and what a curriculum which embraces it would look like. This has included debates about when is the best time to introduce such learning into the curriculum. Yet to deliver change requires professional motivation (Frederickson \& Schluter O'Leary, 1973). Consequently, the debate needs to move on to consider the issues of how to motivate professionals to work together, and indeed, for what purpose. This article describes IPE developments in countries which are reforming their health care systems and seeks to identify the drivers for collaboration and how these translate into different models of 'learning together to work together' (Wild, Iwami, \& Meads, 2003). With a focus on developing countries where interprofessionality is integral to civil society and public service movements the aim is to identify the transferable learning for the UK and other 'first world' countries.

\section{IPE: Fear and trepidation}

In the UK interprofessional education has often met with suspicion. Fears of the introduction of a 'generic worker', of dumbing down and of loss of professional prestige and status have all been noted (Freeth, Meyer, et al, 1999). However, an examination of policy developments, supplemented by a review of the literature around interprofessional education developments across the globe, has not revealed any evidence to support these suspicions. Rather, where new multi-skilled professional profiles have been created (such as Italy's Health and Social Care Workers, Brazil's Health Agents and England's Mental Health Gateway Workers), these new occupations actually support traditional professional profiles, often acting as first point of contact for services.

10 Journal of Practice Teaching 5(3) 2004, pp.5-19 @ 2004. Whiting and Birch 


\section{Innovations in IPE: Learning from developing countries}

Our international research study found that whilst developed countries such as Australia, Sweden, the Netherlands and Finland may be amongst those leading curriculum developments, some of the most innovative examples of developments in multiprofessional education and service delivery may be found in Africa and Latin America. In particular, developing countries are taking the models of action research and problem-based learning and applying them in innovative ways. Two different approaches to interprofessional education are described below as illustrations:

\section{The African approach: community based education}

In many African countries the education of health and social care professionals is community based. For example, Moi University in Northern Kenya has developed the Community Based Education and Service (COBES) Programme. This takes the form of a collaborative partnership between the university and the local population. Students work with local people to identify needs and develop services or initiatives to address these needs. From year two onwards, all trainee doctors and nurses spend at least three weeks per annum located at a community health facility. Students do not simply have the chance to test and extend their skills outside of hospital; they also become integral to the process of identifying and responding to local needs. These have ranged from malaria netting, foster care and HIV education to new water jars, latrines and summer children's day care schemes. Community members are regarded as important members of a team who provide public health related services, including educational initiatives. Within Kenya, as a result, the concept of interprofessional education incorporates professionals working with communities, not just intra- and inter-professional working. Communities are involved in decision-making about health and social care initiatives as well as decisions about placements for trainee medical, welfare and health personnel. As in Ghana and Zambia, this collaboration has been successful in attracting support from nongovernmental organisations, such as CAFOD and Action Aid as part of the sector-wide approach favoured by donors since the 1993 World Bank report on Investing in Health (World Bank, 1993).

11 Journal of Practice Teaching 5(3) 2004, pp.5-19 @ 2004. Whiting and Birch 
In South Africa a new generation of multi-skilled nurses and community health professionals are being trained via interdisciplinary educational programmes. At Western Cape University, for example, a 'Shared Community Based Practice' approach is being piloted, which uses primary health care principles to target the poorest areas via interprofessional programmes. Shared Community Based Practice applies across the faculty and incorporates students of medicine, physiotherapy and public health. Operating in the fourth year of their training the students provide a service as part of their community attachment as well as undertaking local research and needs analyses. In Kwa-Zulu, Natal, Durban University's Community Rehabilitation model of health and social care education uses problem based learning approaches to integrate multidisciplinary contributions and extend local primary care services with trainee Occupational Therapists playing a central design role.

Similar programmes which combine interprofessional education and action research are being promoted in Uganda, Nigeria and other parts of Africa with Sudan pioneering curricula design in community-based joint placements for nurses, doctors and pharmacists. Developments in Sudan (Box 1) illustrate the multifarious ways in which collaboration between trainee professionals and local populations can be encouraged as part of undergraduate education. While these are evidently an economic necessity in poorer countries, they do represent progress on IPE that few developed states have yet achieved.

Uganda provides an example of how epidemiology shapes local services and the educational model required to ensure that professionals are equipped with the skills to deliver them. The prevalence of HIV/AIDS means that services are provided at a number of levels, from the clan, to the village, the county and the district. At each of these levels collaborations between professionals takes place. The collaborative relationships range from those between doctor, nurse, community representatives, social care 'mobilisers', undertakers etc at the village level to public health officials, politicians and educational leaders at district and national levels. These relationships emerge as a response to the combined clinical condition and social need, and community-oriented education is therefore essential. Communities are key members of collaborative partnerships which seek to maintain health and well-being, as well as to respond to disease at the local level.

12 Journal of Practice Teaching 5(3) 2004, pp.5-19 @ 2004. Whiting and Birch 


\section{Box 1:}

\section{interprofessional education integrated across undergraduate curricula}

In Sudan, interprofessional education takes many forms at the level of basic undergraduate education. First there is inter-school education, in which students from different schools undertake joint courses like physiology, basic skills, rural residency and field training. Secondly there are intra-school activities in which students of different programmes in the same school learn together. For example, the Faculty of Applied Medical Sciences at the University of Gezira has three such programmes: Health Psychology, Nursing and Anaesthesia, whose students learn up to $35 \%$ of the curriculum together (Ali, Elgaili, et al, 2002). An example of the third form is the Interdisciplinary Field Training Research and Rural Development Programme (Hamad, 1982). This is a three phase course in which small groups of students from medical and nursing schools are assigned to villages. Here the students work with local people to make a community diagnosis, prioritise health problems, and suggest and implement a solution through community mobilization. Finally they work together to evaluate the intervention. Such education aims to:

1. Reflect the importance of a team work strategy in the field of health;

2. Provide the maximum benefit for the community from the work of students from different disciplines;

3. Ensure that students learn from each other to draw a holistic picture of the state of health in the community;

4. Reduce the cost of the educational process and provide better utilization of the minimal resources available for education in a developing country,

5. Ensure that the longer established Medical Schools provide support to newly established schools (Hamad, 1982)

As well as the advantages of interprofessional education described above, it is also recognised as reducing the cost of the educational process. For Sudan as a developing country this is acknowledged as advantageous and provides an added incentive for its continuation.

Source: Mohamed Elhassan Abdalla, Faculty of Medicine, University of Gezira 
Andrea Wild and Geoffrey Meads

\section{Latin America: the civil society based approach}

The regeneration of professions and the relationships between professions is part of a widespread move to create new civil societies across Latin America, often in response to civil conflict and breakdown. Within Latin America professional development is regarded as a means of restoring public confidence, with professionals becoming role models for new societies. As such, many countries' national targets require services which are dependent upon collaboration between health and social care professionals. Within Chile, for example, as a result of the national health reforms, primary care clinics are being established which include up to nine different professions working together as a team to provide first point of contact services. In the South Metropolitan area of Santiago, for example, the Social Worker is a core member of the triage service, and the primary care centre team is led by a Physiotherapist with integrated multi-disciplinary education support from the Catholic University in the capital.

In Costa Rica, we found eight national strategic level health priorities, with a strong emphasis on prevention. Local Strategy Groups were charged with implementing these priorities, all of which included educational objectives. Telemedicine was used in local primary care clinics as a means of ensuring that the strategic priorities in the 2002 National Health Implementation Plan were supported by team-based training protocols plans and adopted in local areas. The primary care clinics, or ebais, comprises a doctor, nurse practitioner, health technicians and host a variety of other health and social care professionals on a sessional basis. The primary care team all had access to the telemedicine facilities which linked them to both teaching hospitals for specialist expert consultations and also to provincial centres where primary health care and social care advice could be exchanged to facilitate the achievement of key strategic priorities.

\section{Transferable learning}

So what is it that makes interprofessional education and the integration of services work in these countries? Epidemiological, political, economic, professional and educational forces all inform and shape the

14 Journal of Practice Teaching 5(3) 2004, pp.5-19 @ 2004. Whiting and Birch 
structure of health and social care services and the educational models that support them.

Within the UK we are starting to see the organisation of services around long term conditions within some primary care organisations, particularly as a result of the new Family Health Services Contracts for GPs, Dentists and Pharmacists, and the revised three year curriculum for Social Work qualification (NHS Confederation, 2003; Department of Health, 2002). The organisation of services at this level is more akin to that found in many developing countries than the collaborative initiatives which have taken place to date in the UK. Whilst often excellent, these have tended to be independent and at the level of the individual General Practice or Field Work Unit, rather than across a locality. Consequently, the need to ensure that educational models reflect and shape the structure of health and social services is receiving increased attention and recognition in the UK. For example, new initiatives such as the NHS University Institute have sought to involve communities in defining and shaping their programmes and services (NHSU, 2004). The Institute aims to provide education which will 'enable staff to work more effectively across traditional occupational boundaries' (Loughlan, 2003/4), and respond to the needs of local areas whilst utilising local resources, including the knowledge, skills and capacity of members of local communities. This represents a shift away from the traditional discipline-based and experimental model of medical education towards the community development model of education found in many African and other developing countries.

\section{Where next?}

Understanding the forces which motivate professionals to work together is essential if education is to facilitate collaboration in service provision. Findings from our international research project have identified the following factors as representing important motivational forces for collaboration:

- Where education providers possess legitimised power to develop and manage services themselves they become accepted members of the political community for health and social services development.

15 Journal of Practice Teaching 5(3) 2004, pp.5-19 @ 2004. Whiting and Birch 
For example, universities in developing countries which rely on donors, municipalities and students for funding are often very pro-active in the development of interprofessional services, as well as educational initiatives:

- Education which adopts a values-based approach and incorporates the principles of redistributive justice and wider stakeholder participation should be enshrined within professional education if equitable services are to be provided. Where we have found these principles to be lacking health care systems have struggled, for example, to attract GPs to work in rural areas. The public can be left without access to basic health services (as seen in parts of Canada and Australia) and in social care in, for example, the Baltic States of Lithuania and Latvia, provision is dependent upon such emergency relief agencies as the Red Cross and Order of St John.

- Information technology can be used as a shared tool, accessible to all those involved in health maintenance and treatment (like the model described in Costa Rica).

As the many examples of innovations in collaborative practice and the educational developments supporting them presented within this chapter have demonstrated, interdisciplinary, inter-professional practice and learning are now global trends reflecting a cultural change underpinned in local, national and international policy.

So, what does all of this mean for those involved in practice teaching? It is essential that individual professions are equipped with the interpersonal skills necessary for team working and cross-profession collaboration. In particular, the created artificial barriers often found in 'first world' countries between health and social care are gradually being taken down. By placing the client at the centre the necessity of providing a seamless service has been realised. Furthermore, health and social services are now routinely delivered in partnership with an increasing range of stakeholders from the statutory, voluntary, private and community sectors. Opportunities to involve all of these stakeholders in the design and/or delivery of services and educational initiatives are starting to be realised in the UK. There is much that can be learnt from other countries on this matter and, as demonstrated, especially from developing countries for whom such models are often a necessity (for example Uganda's response to the HIV/AIDS epidemic). However,

16 Journal of Practice Teaching 5(3) 2004, pp.5-19 @ 2004. Whiting and Birch 
it must also be noted that within the UK health professionals and the health sector as a whole would benefit from closer collaboration with the social care educational sector, where issues such as team working and community development have historically formed a larger element of training and development.

Within policy health and social care professionals are now conceptualised as team members as opposed to individual representatives of different disciplines and professions (Hargadon \& Staniforth, 2000). Whilst the structural changes to accompany this conceptual shift are becoming more established the necessary behavioural change required is more difficult. And this difficult task falls to practice teachers whose role is to facilitate the learning of profession-specific and generic skills, as well as seek to develop professionals with a client-centred, flexible approach which enables them to work across a variety of settings, frequently as members of multi-specialist teams with new accountability arrangements, often to community committees or the like.

In the UK, employers are now obliged to produce skills profiles for their staff to identify where further training and development is required to facilitate the interprofessional collaboration now enshrined in such policies as the National Service Frameworks around, for example, children's services, older people and mental health service provision. Consequently, professional education must ensure that professionals are equipped with relational skills, as well as an understanding of the contributions other professions can make to health and social care along with the necessary attitude to effectively fulfil both new differentiated and expanded role profiles. These principles are supported by the professional Colleges who now acknowledge the importance of shared learning/training around a number of issues and key skills. Professionals must be adept at working with their own profession and need to feel empowered to with other professions; with partner organisations, including the public, and with policy makers.

Identifying parallel developments in other sites through this brief description of developments in interprofessional education in developing countries demonstrates the potential for transferable learning. Such learning does not have to be limited to first world countries. Whilst context is undoubtedly important, learning about alternative models and processes which can be adapted, if not adopted, transcends contextspecific boundaries. 


\section{Summary points}

The importance of interprofessional education as a means of equipping health and social care professionals with the skills needed to work effectively in team-based and integrated services is recognised across the globe.

In the UK interprofessional developments are regarded as a key element of the modernisation of health and social care.

International research has demonstrated that fears of interprofessional education leading to more generic job profiles are unfounded.

Developing countries are applying interprofessional educational approaches in innovative ways which offer interesting models of relevance to the organisation of professional education in first world countries.

\section{References}

Abdalla, M. (2002) Attitude of first year medical and dentistry students towards Problem based learning. Faculty of Applied Medical Sciences, University of Gezira, Sudan Network: TUFH Conference, Eldoret, Kenya, September 7-12

Ali, E., Elgaili, D., Elhindi, Y. and Hassan, Y. (2002) Meets the health services needs with multi professional education and partnership. Faculty of Applied Medical Sciences, University of Gezira, Sudan Network: TUFH Conference, Eldoret, Kenya, September 7-12

Alwan, A. and Hornby, P. (2002) The implications of health sector reform for human resources development. Bulletin of the World Heath Organization, 80, 1, 56-60

Barr, H. (2002) Interprofessional Education: Today, Yesterday and Tomorrow. LTSN Occasional Paper No. 1. London: Learning and Teaching Support Network

Barr, H., Freeth, D., Hammick, M. Koppel, I. and Reeves, S. (2000) Evaluations of Interprofessional Education. London: CAIPE/BERA

Barrows, H.S. and Tamblin, R. M. (1980) Problem based learning. New York: Springer

Department of Health (2002) Requirements for Social Work Training. London: Department of Health

Forman, D. and Nyatanga, L. (1999) The evolution of shared learning: some political and professional imperatives. Medical Teacher, 21, 489-96

Frederickson, H.G. and Schluter O'Leary, L. (1973) Power, Public Opinion and Policy in a Metropolitan Community: A case study of Syracuse, New York. New York: Praeger

18 Journal of Practice Teaching 5(3) 2004, pp.5-19 @ 2004. Whiting and Birch 
Freeth, D., Meyer, J., Reeves, S. and Spilsbury, K. (1999) Linking interprofessional education to user benefit: of drops in the ocean and stalactites. Advanced Clinical Nursing, 3, 366-372

Funnell, P. (1995) Exploring the value of interprofessional shared learning. in K. Soothill, I. McKay, and C. Webb Interprofessional Relations in Health Care. London: Edward Arnold

Hamad B. (1982) Interdisciplinary Field Training Research and Rural Development Programme. Medical Education, 16, 105-107

Hargadon, J. \& Staniforth, M. (2000) A Health Service of All the Talents: Developing the NHS workforce. Department of Health, London

Loughlan, C. (2003/4) The NHSU Learning Needs Observatory. Eurohealth, 9, 4, 33-37

Meads, G., Ashcroft, J., Barr, H. Scott, R. \& Wild, A. (Forthcoming,) The Case for Interprofessional Collaboration. Oxford: Blackwells Science

Meads, G., Griffiths, F., Wild, A. Iwami, M., Arroyo Laguna, J., Montero, J. and Moore, P. (Forthcoming,) International lessons for new organisational practice in primary care, Seguridad Social Journal

Meads, G., Iwami, M. \& Wild, A. (Forthcoming,) Transferable learning from international primary care developments. International Journal of Health Planning \& Management

Morton-Cooper, A. (2000) Action Research in Health Care. Oxford: Blackwell Science.

Mur, I. \& van Raak, A. (2003) Integration of services and the European Union: does EU policy make sense? International Journal of Integrated Care, 3, 1st October

NHS Confederation (2003) Investing in General Practice. The new General Medical Services Contract. London: Department of Health

NHSU (2004) http://www.nhsu.nhs.uk/news/general/jillbrunt.html, accessed 05/04/2004

Scherpbier, A.J.J.A. (Chairman) (2001) The New Maastricht Curriculum: Best evidencebased medical education. Blueprint New Curriculum Committee, University of Maastricht, Maastricht

Wild, A., Iwami, M. \& Meads, G. (2003) Different systems, same issues, Primary Care Report, 29th October

World Bank (1993) Investing in Health. Geneva: World Bank

World Health Organization (1988) Learning together to work together for health. Technical Report Series Number 769. Geneva: WHO Publications.

19 Journal of Practice Teaching 5(3) 2004, pp.5-19 @ 2004. Whiting and Birch 